\title{
Sosialisasi Efek Positif Dan Negatif Dari Video Games Untuk Anak-anak di RT 001/RW 002 Desa Cibeunying Kecamatan Majenang
}

\author{
Socialization of Positive and Negative Effects of Video Games for Children in RT \\ 001/RW 002 Cibeunying, Majenang \\ Wiga Maulana Baihaqi ${ }^{1}$, Chyntia Raras Ajeng Widiawati ${ }^{2}$, Sarmini $^{3}$ \\ ${ }^{1,2}$ Teknologi Informasi /Teknologi Informasi, STMIK Amikom Purwokerto \\ ${ }^{3}$ Sistem Informasi/Sistem Informasi, STMIK Amikom Purwokerto \\ E-mail: ${ }^{1}$ wiga@ amikompurwokerto.ac.id, ${ }^{2}$ chyntiaraw@amikompurwokerto.ac.id, \\ ${ }^{3}$ sarmini@amikompurwokerto.ac.id
}

\begin{abstract}
Abstrak
Meningkatnya jumlah game online di Indonesia telah memberikan dampak positif dan negatif. Anak-anak yang lalai dengan kegiatan belajar dan mengaji, lupa waktu dan kurangnya interaksi dengan orang tua serta teman bahkan melakukan tindakan kekerasan yang ditiru dari sebuah video game online merupakan beberapa dampak negatif yang ditimbulkan dari game online. Kurangnya pengetahuan anak-anak dan orang tua menjadi salah satu faktor penyebab tingginya paparan dampak negatif dari game online kepada anak-anak. Game online tidak selamanya memberikan dampak negatif namun kurangnya pengetahuan mengenai dampak/efek negatif dan positif dari game online menjadikan angka dampak negatif game online semakin meningkat. Maka pentingnya untuk dilakukan sebuah sosialisasi mengenai dampak dari game online. Kegiatan sosialisasi ini bertujuan untuk meningkatkan pengetahuan anak-anak kepada anakanak mengenai dampak negatif dan positif dari game online sehingga mereka dapat dengan bijak untuk menggunakan waktunya bermain game online dan dapat mendapatkan manfaat positifnya. Kegiatan sosialisasi dilakukan dengan metode pendekatan monologis dan dialogis. Hasil dari kegiatan ini menunjukkan antusiasme peserta sosialisasi terkait dengan materi yang disampaikan dan tanggapan yang positif dari peserta.
\end{abstract}

Kata kunci: game, online, sosialisasi, negatif, positif

\begin{abstract}
The increasing number of online games in Indonesia has had a positive and negative impact. Children who are negligent in learning and studying activities, forgetting time and lack of interaction with parents and friends and even committing acts of violence that are imitated from an online video game are some of the negative effects caused by online games. Lack of knowledge of children and parents is one of the factors causing high exposure to negative effects from online games to children. Online games do not always have a negative impact but the lack of knowledge about the negative and positive effects / effects of online games makes the number of negative impacts of online games increasing. So it is important to do a socialization regarding the impact of online games. This socialization activity aims to increase children's knowledge to children about the negative and positive effects of online games so that they can wisely use their time playing online games and can get positive benefits. The socialization activities were carried out using the monological and dialogical approach. The results of this activity showed the enthusiasm of the socialization participants related to the material presented and the positive responses from the participants.
\end{abstract}

Keywords: game, online, socialization, negative, positive 


\section{PENDAHULUAN}

Dalam 18 tahun terakhir, game online telah mengalami kemajuan yang sangat pesat. Perkembangan ini terlihat dari banyaknya pusat game di kota-kota besar maupun kecil. Berkat perkembangan teknologi, terutama internet, game yang dulunya dimainkan maksimal oleh dua orang dan dalam satu tempat yang sama, sekarang dapat dimainkan bersama dengan 100 orang lebih dalam waktu bersama dan tidak harus dalam satu tempat yang sama. Sejak muncul pertama kali di Indonesia tahun 2000 melalui Counter Strike, game online mulai menjadi perhatian para pengusaha yang ingin memulai mengembangkan jaringan bisnis mereka. Tak lama setelah kemunculannya, setidaknya terdapat 20 judul game online yang beredar dengan genre yang bermacam-macam, diantaranya adalah Nexia (2002), Defense of The Ancients DOTA (2003), Ragnarok (2003), RF Online dan SEAL online (2006), Point Blank (2009), Clash of Clans (2012), Mobile Legends (2016), dan yang terbaru adalah Pubg (2017).

Banyaknya game online yang bermunculan di Indonesia, menjadikan Indonesia pada tahun 2017 menduduki peringkat 16 di Dunia untuk kategori negara paling banyak pemain game aktif dengan jumlah pemain game sebanyak 43,7 Juta. Dari jumlah pemain game aktif di Indonesia, $44 \%$ merupakan wanita sedangkan 56\% merupakan laki-laki. Sedangkan dilihat dari segi usia, pemain game paling banyak di Indonesia yaitu pada usia 21-35 tahun dengan presentase 47\%, dan paling rendah yaitu pada usia 36-50 Tahun dengan presentase $17 \%$, sedangkan yang paling menjadi perhatian adalah pemain game untuk usia anak-anak dan remaja yaitu usia 10-20 tahun dengan presentase $36 \%$.

Jumlah penduduk di RT 001 RW 002 Dusun Cigaru yang masih berada di bangku sekolah yaitu 27 anak, 14 anak masih di bangku sekolah dasar, 7 anak masih di bangku sekolah menengah pertama, dan 6 anak berada di bangku sekolah menengah atas. Mereka berada di rentang usia 10-20 tahun, dimana 20 dari 27 anak merupakan pemain game online aktif. Gambar 1 menunjukkan grafik jumlah pemain game online aktif di RT 001 RW 002 dusun Cigaru.

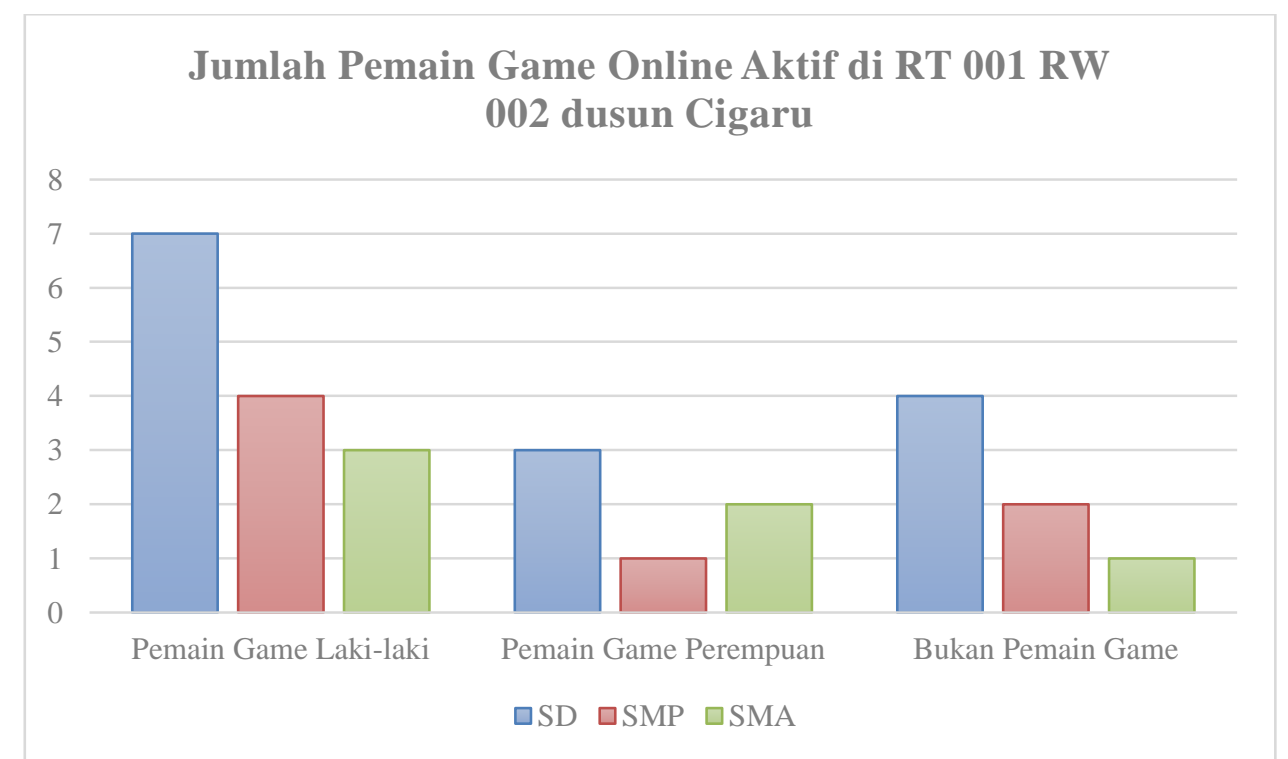

Gambar 1 grafik jumlah pemain game online aktif di RT 001 RW 002 dusun Cigaru

Berdasarkan gambar 1, pemain aktif di RT 001 RW 002 Dusun Cigaru di dominasi oleh anak-anak berjenis kelamin laki-laki, dan mayoritas mereka yang masih di bangku sekolah dasar. Game online yang dimainkan oleh anak-anak RT 001 RW 002 Dusun Cigaru merupakan termasuk jenis permainan video atau video game, dimana permainan yang menggunakan interaksi dengan antarmuka pengguna melalui gambar yang dihasilkan oleh peranti video. Permainan video umumnya menyediakan sistem penghargaan, misalnya skor 
yang dihitung berdasarkan tingkat keberhasilan yang dicapai dalam menyelesaikan tugas-tugas yang ada di dalam permainan [1].

Berdasarkan pengakuan dari anak-anak, mereka bermain game online dengan smartphonenya lebih dari 2 jam dalam sehari, setelah sepulang dari sekolahnya, mereka langsung bergegas membawa smartphone milik pribadi ke tempat titik pusat internet yang ada, sedangkan untuk hari minggu digunakan seluruh waktunya dari pagi sampai sore bahkan malam hari untuk bermain game online. Hal tersebut mereka lakukan setiap hari, sehingga ada berbagai kegiatan yang mereka lupakan, seperti belajar untuk menyiapkan materi sekolah, belajar mengaji AlQuran di Masjid, berinteraksi dengan orang tua di rumah, bahkan mereka sudah lupa bagaimana bermain selain dengan smartphone-nya. Selain anak-anak lupa dengan kegiatan yang positif, beberapa efek buruk yang mengancam dari video game diantaranya adalah peningkatan agresi pada anak-anak. Sebuah meta-analisis komprehensif yang melibatkan lebih dari 100 makalah penelitian menunjukkan bahwa paparan video game kekerasan adalah faktor risiko kausal untuk peningkatan perilaku agresif [2]. Istilah 'permainan patologis' atau kecanduan permainan video sedang dibahas secara luas di kalangan medis meskipun belum diklasifikasikan sebagai gangguan formal apa pun di US Diagnostic and Statistics Manual of Mental Disorders (DSM). Gamer patologis cenderung mengembangkan kecemasan, insomnia, isolasi sosial, dan depresi. Selain itu, faktor-faktor ini bersifat komorbid dalam arti bahwa mereka dapat saling mempengaruhi. Oleh karena itu, permainan patologis dapat mengakibatkan depresi, kecemasan, atau fobia sosial dan tiga yang terakhir dapat membuat anak lebih cenderung dan tertarik pada permainan [3].

Bermain video game juga berpengaruh pada prestasi di sekolah bagi anak-anak, penelitian telah menunjukkan bahwa lebih banyak waktu yang dihabiskan untuk bermain game di layar dapat dikaitkan dengan kinerja akademik yang lebih rendah. Sebuah survei menunjukkan bahwa $47 \%$ pemain daring berat mendapat nilai buruk, sementara $23 \%$ pengguna ringan berkinerja lebih baik daripada mereka [4]. Selain itu, game yang berlebihan dapat berdampak buruk pada kesehatan remaja karena mereka menghabiskan lebih banyak waktu bermain game virtual daripada melakukan latihan fisik. Praktek ini meningkatkan risiko obesitas di masa kecil. Terkadang, anak-anak juga melewatkan makan dan tidur untuk bermain game yang membuat mereka kecanduan. Tatapan konstan dari layar juga dapat merusak penglihatan anak dalam jangka panjang.

Berdasarkan keterangan orang tua dari anak-anak di RT 001 RW 002, anak-anaknya sudah mulai meningkat agresinya, anak-anak mulai mempraktekan perilaku kekerasan dalam kehidupan sehari-hari, selain itu nilai-nilai di sekolah menurun drastis, bahkan sampai malas untuk berangkat sekolah. Kejadian nyata akibat buruk dari video game terjadi juga di Banyumas, Sepuluh anak di Banyumas didiagnosa mengalami gangguan mental akibat kecanduan bermain game online sepanjang tahun 2018. Mereka mendapat terapi di RSUD Banyumas. 7 dari 10 anak itu merupakan siswa Sekolah Dasar (SD) dan Sekolah Menengah Pertama (SMP). Dokter Spesialis Jiwa RSUD Banyumas, Hilma Paramita mengatakan rata-rata pasien sudah tak bisa mengendalikan diri bermain game online. Akibatnya, mereka sudah tak lagi bisa beraktivitas secara normal [5]. Siswa SMP berinisial DF, 15, warga Kota Mojokerto terdeteksi menderita hipertensi primer akibat tak kenal waktu saat bermain game online. Hampir setiap hari DF bersama temannya memilih menghabiskan waktu pulang sekolah di warung internet (warnet) untuk bermain game online. Yang lebih menyedihkan adalah kasus pemuda dari Tangerang Selatan yang bunuh diri akibat koneksi internet pada komputernya tidak berjalan dengan baik saat bermain game online, sehingga pemuda tersebut kesal dan akhirnya menggantungkan diri di rumahnya [6].

Anak-anak maupun remaja sebenarnya tidak perlu untuk dilarang bermain video game, karena dengan bermain video game juga dapat mendapatkan efek yang positif. Tentu saja peran orang tua sangat diperlukan agar anak-anaknya dapat mendapatkan efek yang positif dari bermain game, akan tetapi ketidak mampuan orang tua dalam mengawasi anaknya, dan kurangnya pemahaman apa efek positif yang bisa di dapatkan oleh anak setelah bermain game merupakan masalah yang dihadapi oleh orang tua di RT 001 RW 002 Dusun Cigaru. Salah satu 
efek positif dari video game adalah dapat meningkatkan berbagai keterampilan kognitif seperti alokasi perhatian yang lebih baik, pemrosesan visual, memori, penalaran, dan persepsi, menurut sebuah penelitian yang diterbitkan oleh American Psychological Association. Para peneliti telah mempelajari meta-analisis dari permainan video dan menyimpulkan bahwa efek positif dari permainan kekerasan termasuk peningkatan kemampuan berpikir pemain dalam dimensi yang berbeda, seperti yang dilakukan beberapa program akademik.

Maka dari itu perlu adanya sebuah sosialisasi yang diberikan kepada anak-anak di lingkungan RT 001 RW 002 Dusun Cigaru mengenai efek positif dan negatif video game, hal ini bertujuan untuk memberikan pengetahuan kepada anak-anak mengenai dampak positif dan negatif dari bermain video game sehingga harapannya dari kegiatan ini dapat memberikan dampak yang positif kepada anak-anak di lingkungan RT 001 RW 002 Dusun Cigaru dengan berkurangnya durasi bermain game dan juga kembali melakukan kegiatan-kegiatan positif lainnya seperti mengaji serta mengembalikan minat belajar anak.

\section{METODE PELAKSANAAN}

Sebelum kegiatan dilaksanakan maka dilakukan persiapan-persiapan sebagai berikut:

1. Menentukan waktu pelaksanaan dan lama kegiatan pengabdian kepada masyarakat.

2. Menentukan konten dan menyiapkan materi sosialisasi yang akan disampaikan.

3. Melakukan koordinasi dengan Kepala Desa Cigaru untuk peminjaman ruang sebagai tempat pelaksanaan sosialisasi.

4. Menyiapkan undangan dan sosialisasi jadwal pelaksanaan kegiatan kepada peserta sosialisasi yang merupakan siswa-siswi Sekolah Dasar.

5. Metode pendekatan yang digunakan dalam pelaksanaan kegiatan pengabdian kepada masyarakat ini meliputi metode monologis dan dialogis. Metode monologis berupa pemaparan materi yang disampaikan oleh pemateri pada kegiatan ini sedangkan metode dialogis berupa sesi tanya jawab yang berlangsung antara peserta dengan pemateri

\section{HASIL DAN PEMBAHASAN}

Pada pelaksanaan kegiatan pengabdian ini dalam penyampaian materi sosialisasi kepada anak-anak menggunakan metode pendekatan metode monologis dan dialogis. Metode monologis berupa pemaparan materi yang disampaikan oleh pemateri pada kegiatan ini sedangkan metode dialogis berupa sesi tanya jawab yang berlangsung antara peserta dengan pemateri. Adapun hasil kegiatan pengabdian yang dilakukan berdasarkan diskusi, tanya jawab dan pengamatan langsung selama pelaksanaan kegiatan diperoleh hasil sebagai berikut:

1. Meningkatnya pengetahuan peserta mengenai dampak positif dan dampak negatif dari video game.

2. Kegiatan ini dihadiri oleh 20 orang peserta. Tanggapan peserta sangat positif karena peserta memperoleh pengetahuan mengenai dampak positif maupun dampak negatif dari video game. Sehingga peserta dapat menerapkan hal-hal positif yang diperoleh dari sosialisasi tersebut. Peserta bisa membatasi diri dalam bermain video game karena telah mengerti dan memahami bahwa bermain video game secara berlebihan dapat memberikan banyak dampak negatif.

3. Tanggapan positifpun diperoleh dari salah satu orang tua yang juga ikut serta hadir pada sosialisasi yang telah dilaksanakan. Berdasarkan tanggapan salah satu orang tua dari anak yang mengikuti kegiatan dapat dilihat bahwa sosialisasi seperti itu memang perlu diberikan kepada anak-anak maupun orang tua. Dengan demikian, anak-anak maupun orang tua mengerti hal baik dan hal buruk dari game.

4. Pada sesi tanya jawab, peserta diberi keleluasaan untuk bertanya terkait materi sosialisasi. Pada sesi ini peserta yang belum memahami tujuan dan beberapa hal yang disampaikan akan dijelaskan kembali secara detail oleh pemateri. Pemateri juga mengajukan beberapa 
pertanyaan terkait materi yang telah disampaikan untuk menguji pemahaman peserta dari materi yang telah disampaikan.

\section{KESIMPULAN DAN SARAN}

1. Kesimpulan

Kegiatan pengabdian kepada masyarakat dapat berjalan dengan baik dan memperoleh tanggapan positif dari peserta sosialisasi yaitu 20 anak yang merupakan siswa SD di daerah Desa Cigaru. Selain itu tanggapan positif juga diperoleh dari salah satu orang tua yang juga ikut menyaksikan berlangsungnya kegiatan tersebut.

2. Saran

Diharapkan sosialisasi ini dapat dilaksanakan untuk desa lain, sehingga dapat membantu dalam meningkatkan pemahaman akan dampak positif dan negatif dari video game. Selain itu, diharapkan sosialisasi seperti ini juga bisa disampaikan tidak hanya ke siswa SD tapi juga ke orang tua yang harus memahami baik buruknya video game.

\section{DAFTAR PUSTAKA}

[1] Winter, David. (2018). Video game. http://www.pong-story.com/intro.htm (Diakses 1 Januari 2019)

[2] Anderson, C. A., Shibuya, A., Ihori, N., Swing, E. L., Bushman, B. J., Sakamoto, A., ... Saleem, M. (2010). Violent video game effects on aggression, empathy, and prosocial behavior in Eastern and Western countries: A meta-analytic review. Psychological Bulletin, 136(2), 151-173.

[3] Prot, S., Anderson, C. A., Gentile, D. A., Brown, S. C., \& Swing, E. L. (2014). The positive and negative effects of video game play. In A. Jordan \& D. Romer (Eds.). Media and the Well-Being of Children and Adolescents (109-128). New York: Oxford University Press.

[4] Rideout, V. J., Foehr, U. G. and Roberts, D. F. (2010) Generation M2 Media In The Lives Of 8- To 18-Year-Olds. Edited by T. Boston and K. Kauka. Menlo Park: Henry J. Kaiser Family Foundation.

[5] Aziz, Abdul. (2018). Kecanduan Game Online, 10 Anak di Banyumas Alamai Gangguan Mental. https://www.merdeka.com/peristiwa/kecanduan-game-online-10anak-di-banyumas-alami-gangguan-mental.html (Diakses 2 Februari 2019)

[6] Luthfi, Ahmad. (2016). Korban Meninggal Dunia Saat Bermain Game. https://techno.okezone.com/read/2016/08/09/326/1458986/korban-meninggal-duniasaat-bermain-game-online (Diakses 3 Februari 2019) 